\title{
CAE Systems for Structural Analyses of Layered Composites
}

\author{
Gabriela Kuchtová \\ ${ }^{1}$ Technical University of Košice, Faculty of Manufacturing Technologies with a seat in Prešov, Štúrova 31, 080 \\ 01 Prešov, Slovakia
}

\begin{abstract}
:
Composite materials have several advantages over conventional types of materials, especially in terms of weight and "functionality". They also have several disadvantages (e.g. delamination, microcracks,), which engineers and designers try to minimize to such a level that they can match the common material. The development and design of composites is accompanied by the tools of CAE systems, which save time and financial costs associated with physical prototyping.

The tools of CAE systems are used e.g. to analyse the robustness and performance of components and assemblies, including simulations and optimizations of products and manufacturing tools, thus assisting engineers and designers in making decisions as an information provider.

In addition to the constant development of new materials, production technologies and processes, software companies and manufacturers of CAE systems also strive to keep pace with the development of CAE systems themselves. We are looking for tools to improve processes for faster processing and providing quality information, better use of computer resources and technical pre-processing of information, creating more optimized designs, using simulations to determine the properties of new materials such as composites and new proprietary microstructures, more implicit dynamic solutions, etc.

The article offers a brief overview of the areas of CAE systems and an overview of relatively well-known CAE software used for structural analysis of layered composite materials.
\end{abstract}

Keywords: Computer Aided Engineering (CAE), composite materials, software, layered structure/composites. 


\section{Introduction}

The goal of manufacturing companies is to produce products so that the products meet the quality and functionality required by customers, so that it is economically beneficial for the company and that it is in accordance with regulations by the state. The development of technologies and production processes and the development of the materials themselves are also advancing with the ever-increasing demands on the part of customers. The basic materials are replaced by composites for their better mechanical properties, which can fully replace them. The intention is to optimize the production process, reduce costs, and modernize production and also the products themselves with regard to exhaustible and nonrenewable natural resources.

The composite material consists of two or more components of different chemical composition with their different physical and mechanical properties. The primary part is formed by a continuous phase (matrix), which has the role of a binder, and the secondary part is formed by a discontinuous phase (reinforcement), which has a reinforcing character. Reinforcement most often occurs in particulate or fibrous form.

The layered structure of composites is composed of three or more layers of different materials (core and outer layers - sandwich structure), or one type of material with different fiber orientation (laminates).

The choice of materials in the formation of composites is adapted to the requirements that the final layered structure should meet. It is effective if it consists of two solid outer layers that are stressed by compressive and tensile forces and a low-density core that can transfer shear forces between the outer layers.

All newly formed composite materials require an individual approach to the study of their basic properties, such as strength, flexibility, hardness, damping, density and the like.

\section{CAE systems and manufacturing company}

The essence of the development is to streamline work, optimize the transformation process and ensure competitiveness for the further possible development of the company. Production automation should focus not only on the technological process but also on the preparatory work, which is very demanding in terms of time.

Various computer-aided systems are being developed to support the optimization of production as a whole. Their task is to design components, technology, production and other engineering work and they are an important part of the engineering industry but also other industries, e.g. energy, automotive, aerospace, electronics, etc. The challenge for the construction of composite structures is to design both the structure and the material so as to fully support the load that will be applied to the composite material during its operation while achieving optimum performance. 
The use of CA systems (Computer Aided Systems) is intended to facilitate development work and shorten the time of various production technologies. CA systems represent a set of subsystems used in production, see. Figure 1.

Figure 1: Subsystems CA systems

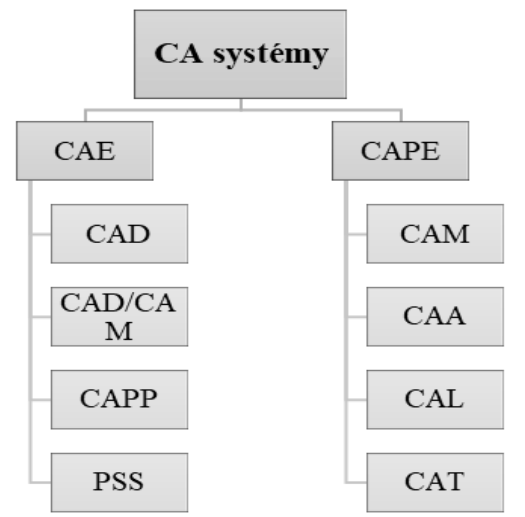

CAE - Computer Aided Engineering - PC support of engineering works, which includes development-design and planning stages [1]:

- $\quad C A D$ - Computer Aided Design,

- CAPP - Computer Aided Planning Process,

- $\quad$ CAD-CAM - Computer Aided Design and Computer Aided Manufacturing,

- $\quad$ PSS - Production Planning and Management.

CAPE - Computer Aided of Product Engineering - PC support of technological-implementation stages [1]:

- $\quad$ CAM - Computer Aided Manufacturing,

- $\quad$ CAA - Computer Aided Assembly,

- CAL - Computer Aided Logistic,

- $\quad$ CAT - Computer Aided Testing.

CAPE functions as a subsystem - CIM - Computer Integrated Manufacturing, which includes PC support of all activities related to the implementation of the product production itself [1].

Currently, there are many commercial and non-commercial CAE software that use the finite element method for various engineering disciplines. They help handle a wide range of problems from simple linear static analysis to non-linear transient analysis, represent the whole process of the product manufacturing process and also include technical process support as they allow tests and simulations of physical product properties without the need for a physical prototype.

Using CAE systems, we can determine [2]:

- deformation stress analysis of components and assemblies using the Finite Element Method (FEM), Finite Element Method Analysis (FEA),

- thermal and flow analysis of computational fluid dynamics (CFD),

- body system (MBD) and kinematics,

- analytical tools for process simulation for casting, stamping and pressing,

- Optimization of the product and production process.

In general, CAE systems are divided into 3 phases [2]: 
- pre-processing - design and creation of so-called calculation model and environmental factors,

- analysis solution/processing - model generation, the solution itself,

- Post-processing - visualization and export of output, analysis - interpretation of results.

The article must be divided into chapters. Introduction and conclusion are obligatory. It is recommended to adjust body of the paper to the common organization structure of scientific papers - IMRaD (Introduction, Methods, Results and Discussion).

\section{CAE systems and their functionality}

The classic CAE process consists of pre-processing, solution and post-processing steps. In the pre-processing phase, engineers model the geometry and physical properties of the design, as well as the environment in the form of applied loads or constraints. Furthermore, the model is solved using a suitable mathematical formulation of basic physics, which is a kind of tool to evaluate the proposed technology in terms of part manufacturability and optimization of the proposed process. In the post-processing phase, the results are submitted to the technician for review.

A basic understanding of the FEM principle is required for the effective use of any software in the field of CAE systems. It is a mathematical method, the basis of which is the division of the solved area into finite elements and whose procedure is described in [3].

In order to draw conclusions from the offered CAE systems, it is important to know and enter qualitative input elements for the calculation. The accuracy of the simulation depends on the accuracy of the input data and the defined boundary conditions. In general, among the "basic" input elements, respectively. "Basic" workflow for analysis, we can consider the following steps [4]:

- creation of a network and model of a sample of a material or part - geometry (entering coordinates) of a sample or part,

- Material assignment to the network - name and properties of the material while the software can offer different number of parameters for FEM needs (density $(\rho)$, tensile modulus (Young's modulus - E), shear modulus (G), Poisson's constant $(\mu)$, material limit states such as Re and Rm, service life curves $S$ - N, coefficient of thermal expansion, thermal conductivity, etc.) $[5,6]$. The type of material with properties must be assigned to the individual layers of the composite sample separately. We also determine the directions of the fibres, the angle of rotation of the layers, the thickness of the material, etc.,

- Setting of boundary conditions - joining individual layers of material into one unit (distance between layers must be greater than actual distance), distributed load $\mathrm{f}(\mathrm{x})$ (sample attachment, model load by forces, pressures and moments, self-weight, temperature, etc.) 
- Evaluating results and finding bottlenecks.

The whole simulation procedure is repeated until all the bottlenecks are removed. The product criteria must be satisfactory and practically confirmed.

Sources of determining material properties can be analytical, numerical, experimental or a combination thereof.

One of the designer's tasks in designing a structure is to predict how the structure will behave in different situations. The principle of analytical models of composite profile properties is that using multicriteria analysis the algorithm selects a suitable profile according to the requirements from the database of fundamental profiles (selection part) and then the iteration loop determines the optimal size and composition of the profile (calculation part). This method of solving engineering problems is especially suitable for very simple tasks, as it is a comparison of results with known solutions listed in tables, catalogues, etc.

Therefore, in practice, the designer more often encounters numerical methods. In order to be able to appropriately oversize individual nodes and parts of a new structure, it must perform various types of calculations using computer technology, e.g. using the just mentioned CAE systems.

Experimental sources for determining material properties represent performing an experiment on a prototype sample followed by documented reproduction of the results. This type of resource is the most time consuming.

The output is graphically visualized data e.g. in the form of simulations, vector, ISO, point display, graphic display in section, etc. The results point out various failures, failures or, conversely, confirm the correctness of the design. In general, these types of outputs are very beneficial because the human eye can evaluate a large amount of processed data relatively quickly and draw a consequence from it. The quality and types of outputs differ in content value depending on what outputs the software can generate; i.e. what functions it is equipped with.

The best-known CAE systems that are suitable for the analysis of the mechanical behaviour of composite materials are e.g. ANSYS, ABAQUS, MATLAB, SimScale, SolidEdge, CreoSimulate, etc. In addition to the mentioned commercial software, there are software developed by universities and the research companies. The research and development goal are to eliminate the high computing power requirements of FEM. Since composite materials are a combination of two phases with different physic-mechanical properties, at the phase interfaces, the high stress concentrations arise. This requires a high number of conventional finite elements, whether the fibre, particle or structured composites. Newly developed computational methods are based on the boundary element method, the method of fundamental solutions, collocation methods, mesh-reducing methods etc. An example of a mesh-reducing computational method for short-fibre composites is the Method of Source Functions that does not require a classical mesh [7-9]. There are also other specialized calculation methods for short-fibre composites, which are compared in [10]. 


\subsection{ANSYS Composite PrepPost}

ANSYS Composite PrepPost software is a specialized tool for composite layout modelling and fault analysis. Can generate layered implicit and explicit structural and thermal composite models, as well as fluid analysis, strength analysis, vibration simulation, impact simulation to determine material life. In addition, ANSYS Composite Cure Simulation simulates the curing manufacturing process, the vulcanization process, and predicts residual stresses and deformations caused by the process. [11]

Figure 2: Stress distribution in laminate in ANSYS [12]

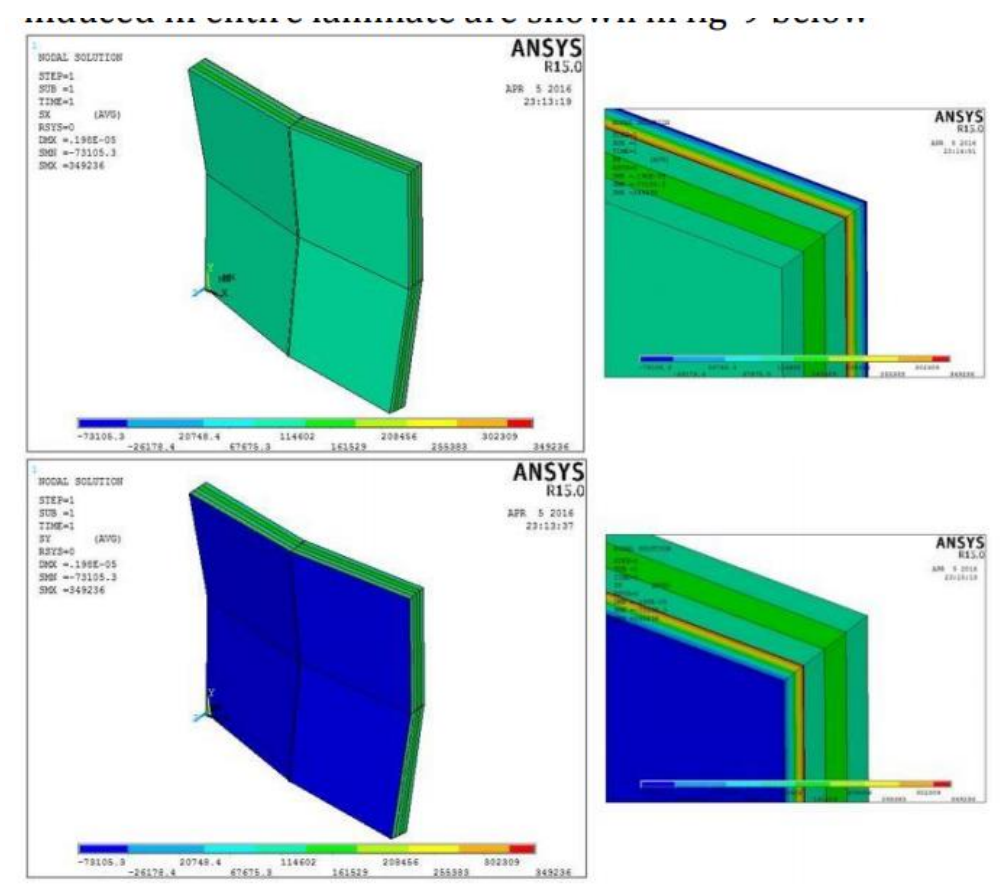

Figure 2 shows a model of a laminate in the ANSYS program, the load of which is along its edges. Stress loads and stresses are analysed for all layers of the laminate separately and then as a whole. The layer with the lowest value of the strength ratio fails first and thus this layer gives the load FPF (first ply failure). The strength ratio in ANSYS represents the inverse force ratio. Failure theories are used to calculate the last ply failure (FPF) and last ply failure (LPF) loads using the obtained stresses and to compare the strength ratios for both cases. [12]

\subsection{ABAQUS}

The ABAQUS Unified FEA product package is part of the SIMULIA brand and provides complete solutions for common and sophisticated technical problems involving a wide range of industrial applications. For example, in the automotive industry, full load, dynamic vibration, multiple systems, impact effects, nonlinear static, thermal, and acoustic or structural connections can be considered when designing a vehicle using a common model data structure and integrated solution technology. [13] 


\subsection{SolidEdge}

SolidEdge is a complete hybrid 2D / 3D CAD system that uses synchronous technology to accelerate design, faster change, and improved imported reuse. SolidEdge Simulation allows you to digitally validate part and assembly designs in a SolidEdge environment based on an FEA solution. It includes definitions of boundary conditions for realistic environments, full motion simulation, stress analysis and simulation, thermal simulation, vibration simulation, fluid analysis. The system is based on the proven Femap finite element model and NX Nastran technology. [14]

\subsection{MATLAB}

MATLAB is a programming, modelling and simulation tool whose basic data element is an array that does not require dimensioning. This allows you to solve technical problems with the calculation, especially those that have a matrix and vector composition. As it is a programming software, it is necessary for the user to have the knowledge to program and then compile a calculation program. In practice, there are 2 commercially available "versions" available, namely the professional and student versions. The professional version includes a basic set of tools and other tools must be purchased separately [15]. Matrix size is limited by memory and is costly [15]. The student version includes a basic set of tools, the Simulink addon software for simulations and modelling of dynamic systems, and "symbolic" toolkits [15]. The size of the matrices is large but also limited and, unlike the professional version, it is cheaper [15].

\subsection{SimScale}

SimScale, unlike the previously mentioned software, provides access to engineering simulation through a web browser and is one of the largest CAE communities in the world. The SimScale web platform allows engineering professionals to perform CFD, FEA, thermodynamics, acoustics and particle analysis, making simulation technology accessible to anyone. This removes the barriers that accompany traditional simulation tools, such as high installation costs, licensing fees, deployment of high-performance computing hardware, and required software updates and maintenance. [16] 


\subsection{Femap}

Femap is an advanced technical simulation application for creating, editing, and importing or reusing finite element models with complex network-focused products or systems. It is used to model components, assemblies, or systems and to determine the behavioural response for a given operating environment. It allows to define and modify laminate layers, create a model network, provides powerful visualization and evaluation of graphical results (16). It can import an existing model from any major CAD system (Solid Edge, Solidworks, CATIA, Creo, etc.) [17].

\subsection{NX Nastran}

NX Nastran is an ideal tool for the analysis of composite structures with individual representation of layers in a two-dimensional element using a PCOMP card. The PCOMP card can simulate various types of composite material structures, from rigid laminates to honeycomb cores. The software provides analysis of stress, vibration, buckling, structural failures, heat transfer, acoustics and aeroelasticity. [17]

\subsection{Fibersim}

The simulation software NX Nastran, Pro Engineer and Catia is enhanced with Fibersim software, which simplifies the task of designing, analysing and manufacturing composite parts by providing tools for easily editing, updating and iterating composite designs. This allows you to work with combinations of material types, fibre orientation, symmetry, etc. [17]

\subsection{Catia - Composites Design 3}

Another software designed for composite materials that can reduce the time when designing composite parts is the program Catia - Composites Design 3 (CPD). It is an extended version of the Catia V5 software and is used in both the preliminary and detailed design phases, while it can take into account the needs of production in the design phase. It provides tools for simple modelling, automatic generation of layers, including alternation of layers with stacking rules, control of composites (numerical analysis), simulation of fibre behaviour, etc. [18] 


\subsection{Creo Simulate}

Creo Simulate is 3D CAD software and is one of the applications of integrated software PTC Creo, designed for product design through construction after analysis, for more efficient data sharing between designers and other partners from any CAD source, for the ability to combine parametric and direct modeling and software flexibility. It provides structural, thermal and vibration analytical solutions with the possibility of FEA 3D prototypes. The software can be used as a stand-alone application or in combination with other applications and offers structural analysis, linear thermal analysis at steady state, material library, model networking, optimization and design processing [19].

Figure 3: Mises stress in individual layers $0^{\circ}, 15^{\circ}, 30^{\circ}$

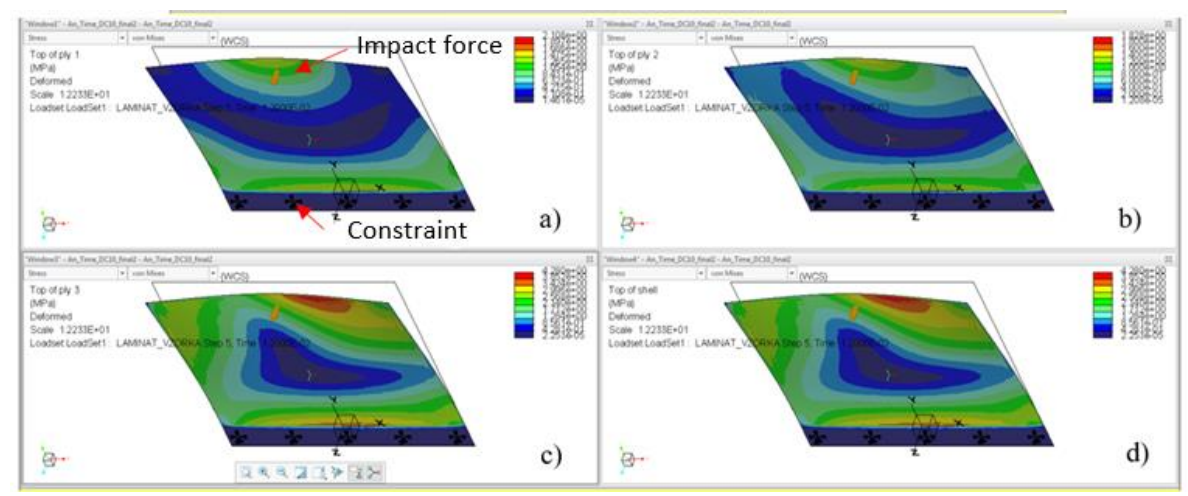

In figure 3 is an example of output from the commercial computer software Creo Simulate, which has implemented classical lamination. The model in fig. 3 consists of 3 laminated layers of twill fabric made of glass fibres, the basic warp being oriented at an angle of $0^{\circ}, 15^{\circ}, 30^{\circ}$. The computational model is embedded in the lower part and excited in the upper part by the impact force F. It is possible to see the different distribution of the Mises stress in the individual layers in fig. 3a), 3b), 3c) as well as in the composite as a whole.

\section{Conclusion}

Currently, the market offers a number of computer support computer systems. When choosing the right software, you need to be able to take into account the criteria and area of interest of use. The ratio of the highest price = best quality does not always apply. Therefore, it is necessary to carefully consider what I need the software for and what I expect from it. Then we take into account other criteria, such as type of software (desktop / web application), ease of use, compatibility with other CA software, functions (statistical, mathematical functions, a wide range of simulations and analyses, the ability to use previous information for forecasting,), the price of the software.

The main benefit of computer-aided engineering software is time savings and thus faster product / material development, cost savings as no physical prototypes are needed in the development phase, higher efficiency and productivity of engineering work.

It is necessary to keep in mind the correct understanding of how to use the software, i.e. to be able to enter quality inputs and correctly evaluate the results. This involves continuous training in the field, because the company does not benefit from the misuse of any software. 


\section{Acknowledgment}

The author would like to thank the Slovak Research and Development Agency for supporting this research through the grant no. APVV-18-0316.

\section{References (TNR 12pt. bold)}

References in text should have this form (surname, year), for example:

1 author:

1 author and the same year of publication:

2 authors:

3 authors:
(Krugman, 2012)

(Hoffman, 2012, A), (Hoffman, 2012, B)

(Krugman \& Hoffman, 2014)

(Hoffman et al., 2012)

\section{References}

[1] Kender, Š. (2011). "Use of CAX technologies in the automotive industry" (Využitie CAX technológií v automobilovom priemysle) Transfer inovácií. [Online]. 19, pp. 229233. Available: http://www.sjf.tuke.sk/transferinovacii/pages/archiv/transfer/192011/pdf/229-233.pdf

[2] "Computer Aided Engineering Cae" [Online]. Available: https://www.plm.automation.siemens.com/global/en/our-story/glossary/computer-aidedengineering-cae/13112

[3] Murín, J., Hrabovský, J., Kutiš, V. (2014). Finite Element Method. Selected chapters for mechatronics. (Metóda konečných prvkov. Vybrané kapitoly pre mechatronikov). Bratislava: Slovenská technická univerzita v Bratislave, pp. 142.

[4] Zubík, M. (2018). Composite product optimalization. (Optimalizace kompozitního výrobku), Diploma thesis, Tomas Bata University in Zlín, Czech republic.

[5] Ivančo, V., Vodička, R. (2012). Numerical methods of mechanics and selected applications (Numerické metódy mechaniky a vybrané aplikácie), SjF TU v Košiciach, Košice, pp. 285.

[6] Burák, J., Ostertag, O. (2010). Fundamentals of design of structural elements using the finite element method (Základy projektovania konštrukčných prvkov pomocou metódy konečných prvkov), Elfa, Košice, pp. 324.

[7] Murčinková, Z., Novák, P., Kompiš, V., Žmindák, M. (2018). Homogenization of the finite length fibre composite materials by boundary mesh less type method. Archive of Applied Mechanics, vol. 88, no. 5, pp. 789-804.

[8] Kompiš, V., Murčinková, Z. (2014). Thermal properties of short fibre composites modeled by mesh less method. Advances in Materials Science and Engineering, pp. 8.

[9] Kompiš, V., Murčinková, Z., Očkay, M. (2011). Temperature fields in short fibre composites, in Computational modelling and advanced simulations. Springer, Dordrecht, pp. 99-116. 
[10] Kompiš, V., Murčinková, Z., Rjasanow, S., Grzibovskis, R., \&Qin, Q. (2010). Computational simulation methods for fiber reinforced composites. Frontiers of Architecture and Civil Engineering in China, vol. 4, no. 3, pp. 396-401.

[11] “About ANSYS“ [Online]. Available: https://www.ansys.com/about-ansys

[12] Patill, A. S., Khadabadi, U. B. (2016). ANSYS as a Tool to Perform FEA and Failure Analysis of Hybrid Laminated Composites. International Research Journal of Engineering and Technology (IRJET), vol. 03, pp. 1235-1241.

[13] "Abaqus" (February 2020). [Online]. Available: https://www.sheffield.ac.uk/itservices/research/software/abaqus

[14] “Top software for 3D design" (Špičkový softvér pro 3D návrh) [Online]. Available: https://solidedge.siemens.com/cs/solutions/products/3d-design/

[15] Kalechman, M. (2018). Practical Matlab Basics for Engineers. Boca Raton: CRC Press, pp. 712.

[16] Felföldi, A. (January 2019). Comparison of CAE Software for Engineering Consultinf Firms. [Online]. Available: https://www.simscale.com/blog/2018/10/cae-softwarecomparison/

[17] "Composite Design and Analysis Software" [Online]. Available: https://structures.aero/composite-analysis-software/

[18] "CATIA V5-6R2016 Drives Higher Design Excellence" [Online]. Available: https://www.3ds.com/productsservices/catia/products/v5/portfolio/domain/Mechanical_Design/product/CPD/?woc=\%7B $\% 22$ category $\% 22 \% 3 \mathrm{~A} \% 5 \mathrm{~B} \% 22$ category $\% 2 \mathrm{Fchampions} \% 22 \% 5 \mathrm{D} \% 7 \mathrm{D} \& w o c k w=$ card_co ntent_cta_1_url\%3A\%22https\%3A\%2F\%2Fblogs.3ds.com\%2Fcatia\%2F\%22

[19] "Creo Simulation" [Online]. Available: https://www.ptc.com/en/products/creo/simulation 